\title{
Implementation of a sustainable enterprise risk management framework: The Administrator on Duty model
}

\author{
Linda L. Vila*1, Vito Buccellato ${ }^{2}$ \\ ${ }^{1}$ Department of Health Care \& Public Administration, Long Island University, Post, Brookville, New York, Unites States \\ ${ }^{2}$ VB Health Management Solutions, Staten Island, New York, United States
}

Received: December 7, 2015

DOI: $10.5430 /$ jha.v5n2p 80

\author{
Accepted: January 7, 2016 \\ Online Published: January 13, 2016 \\ URL: http://dx.doi.org/10.5430/jha.v5n2p80
}

\begin{abstract}
Background: Today's health care landscape requires a new standard of service delivery aimed at quality outcomes, cost-effective provisions of coordinated treatment, and access to equitable care. This standard has brought emerging risks that pose threats to the operational and financial well-being of health care organizations, especially safety net hospitals. The establishment of enterprise risk management (ERM) programs guided by the efforts of efficacious health care managers will promote deeper risk analysis, engagement of the entire health care organization, and structured, coordinated and cohesive mitigation responses to risk exposures.

Objective: To establish and implement an ERM program using the Administrator on Duty (AOD) model that will promote a patient-centric paradigm of care while optimizing organizational performance and mitigating risk and exposure.

Results: The AOD model significantly contributes to all phases of ERM, particularly risk identification, risk assessment, risk response and monitoring. The model, as perceived by both AODs and hospital senior leadership, provides tremendous benefits to a health care organization. These include, among many others, a substantial leadership presence, dynamic risk mitigation efforts, continuous education to staff and facilitation of problem solving and conflict resolution.

Conclusions: The AOD program is a vital constituent of an ERM endeavor. AODs are pivotal to managing the global risk terrain of a health care organization and play a substantial role in promoting patient, staff and visitor safety while working to ensure potential and actual risk issues are addressed timely and appropriately.
\end{abstract}

Key Words: Enterprise health care risk management, Administrator on Duty, Health care management model, Hospital managers

\section{INTRODUCTION}

The health care industry and landscape is complex, challenging and currently undergoing a substantial change. The implementation of the Patient Protection and Affordable Care Act has altered the way health care is delivered and has shifted care to a patient-centric, integrated, value-based, preventative, transparent paradigm. ${ }^{[1,2]}$ This new standard of service delivery has brought with it greater oversight and control from regulators, payors, oversight entities and public interest groups. It has also brought emerging risks that pose threats to the financial and operational well-being of health care organizations. To ensure that health care organizations provide improved quality outcomes, cost-effective services and equitable access to care while maintaining patient safety

*Correspondence: Linda L. Vila; Email: Linda.vila@liu.edu; Address: 720 Northern Blvd., Brookville, New York, 11548, Unites States. 
and sustainability, ${ }^{[3]}$ they must employ competent health care managers and implement effective risk management programs, specifically enterprise risk management (ERM) programs. ERM promotes efficiency, effectiveness and responsiveness in the delivery of health services while mitigating risks to the organization and optimizing organizational performance.

This paper examines the managerial competencies needed in today's demanding health care climate. It discusses ERM, matches managerial competencies with effective ERM, and introduces a unique ERM framework implemented in a New York City hospital: the Administrator on Duty (AOD) model. The utility and value derived from the model as perceived by organizational senior leadership as well as from the managers themselves who served as AODs are explored.

\subsection{Health care managerial competencies}

Managerial roles in health care and, consequently, managerial competencies have morphed over time. ${ }^{[4-10]}$ Competencies have progressed from generic management, financial, and clinical proficiencies to people management, selfmanagement, and strategic management skills, reinforcing the fact that health care is a "human" industry and inclusion coupled with teamwork is essential to avoiding a risk adverse environment of health care delivery. ${ }^{[1-14]}$ While competencies can be context dependent and developmental, the Healthcare Leadership Alliance compiled a Competency Directory that provides a common framework and lexicon for a variety of health care managers in a range of roles and settings which serve to define the field ${ }^{[15]}$ and promote an ERM movement. The Directory categorizes managerial competencies into five critical domains and prescribes that managers should demonstrate competence in aspects of all five domain areas: Communication and relationship management, leadership, professionalism, knowledge of health care environment, and business skills and knowledge.

Managerial competencies, however, should not be limited to principles of health care management as both clinical and business endeavors. Rather, the integration of complementary disciplines should be considered. Health care systems should adopt useful principles and models of public health practice as new competencies for health care management. ${ }^{[16]}$ These competencies include understanding how a specific population manifests disease and how this creates demand in the health system; comprehending the social determinants of health; using opportunities to create health system loyalties; and working in interprofessional teams to collaborate and effectively manage overall care delivery. Public health practice enhances the health services value equation by responding to the health care landscape of accel- erated integration on the provider side of the equation and the transformation of financial, operational and strategic risk for covered populations on the payor side. It offers a guide as large health systems seek to become the one-stop shopping provider for defined populations and strive to engender the loyalty of populations so that they refrain from moving from health system to health system. ${ }^{[17]}$

\subsection{Enterprise risk management}

ERM is an integrated process to manage risks found across health care organizations and identify opportunities for improvement in health care delivery and patient safety. It is a comprehensive, holistic approach that recognizes risks are not isolated but, rather, inter-related to, and inter-dependent on, all areas in an organization as well as the organization's overall strategic plan. Such a methodology requires organizations to tackle issues systematically and eliminate functional silos. The focus is one of proactivity not reactivity.

Since ERM follows a portfolio approach, healthcare organizations are able to implement a structure that enables leadership to make more efficient and timely decisions based on continuous risk identification, assessment and response as well as an enterprise-wide understanding of the impact. This structure is a top-down process that is driven by the organization's governing body, management and key personnel. A single view of overall risk is established which envelopes the identified risks that face the organization. In short, ERM is traditional risk management on a panoramic scale.

There are five components to ERM in healthcare as adapted from the generic model ERM program established by the Commission of Sponsoring Organizations of the Treadway Commission (COSO). ${ }^{[18]}$ The first component, defining the organization's risk appetite and risk tolerance, involves determining the amount of risk, on a broad level, an organization is willing to accept in pursuit of value and its willingness to accept risk outside of its original risk parameters in order to achieve its objectives.

The second element, identifying risks, occurs when an organization examines all internal and external events that could impact the realization of strategic goals. By dissecting all possible and actual events and identifying their impact and causes, an organization can better assess the likelihood and severity of impact of each of them. It can also assess opportunities that the events present. This is a continuous process and can include a loss of assets, business interruption, privacy and safety breaches, professional liability, and fraud and abuse among many others. Such events can affect the organization's reputation and standing in the community and with oversight agencies, respectively, and can offer signif- 
icant financial, legal and regulatory exposure. Risks are often categorized into risk domains and EMR recognizes the six risk domains of operational, financial, human, strategic, legal/regulatory and technological.

Third, assessing risks comprises evaluating all events to determine the interrelationship of the risks across the entity and prioritizing their degree of impact. The use of assessment tools and metrics within an accountability context are often helpful when carrying out assessment. This, too, is a continuous process.

The fourth component, responding to risks, focuses the organization toward establishing and implementing risk reduction strategies to address the assessed risks. Actions are typically contingent upon the organization's risk tolerance, a cost-benefit analysis of responsive actions, and the degree to which the action would impact the occurrence of the risk. Risk responses may include avoiding or evading, accepting, reducing, and sharing or transferring risk.

Finally, the fifth element, risk monitoring, looks at the ongoing activity undertaken at all levels of the organization with respect to the first four components of the ERM process. $^{[19-21]}$

\subsection{ERM and managerial competencies}

Health care managers who possess many if not all of the health care managerial competencies previously mentioned are essential to the success of an ERM program because they play a sizeable role in the ERM process. They must be leaders, strategists, catalysts and task-masters guiding the program as well as exhibit a solid understanding of the health care delivery environment and the business of health care. Substantive knowledge of industry market forces and systems, especially for the local service continuum, is an imperative, as is procedural knowledge of the organization's functions and processes. Effective ERM further demands that managers hold both "hard" and "soft" skills. Hard skills of particular importance are the cognitive ability to process a large amount of information, technical expertise and familiarity with health care laws, rules, regulations and standards. Soft skills revolve around communication, negotiation, facilitation, coordination, anticipation, troubleshooting and team building. Managers must collectively appreciate and promote a common, amalgamated risk management strategy as the way of doing business.

\section{MeTHODS}

\subsection{ERM: the AOD model}

The senior leadership of a New York City safety net hospital ascertained that ERM was the appropriate direction in which to steer its Risk Management program. To this end, it was recognized that new and creative means for capturing the expansive perspective on enterprise risk was needed and concluded the imposition of "global" managers or AODs, specifically on off tours, could play a significant role in many, if not all, of the components of an ERM program. In particular, they could aid in risk issue identification, intervention mitigation and outcomes monitoring. AODs could provide acute assistance to risk management leadership and other members of the ERM team with "connecting the dots" among risks throughout the organization.

The development of the AOD program began with the general observation that operational matters which threatened the financial, strategic and legal well-being of the organization repeatedly arose during the off tour shifts and a nursing supervisor, who typically was covering these shifts, was wellequipped to address clinical issues but lacked the expertise to address the operational issues. Off tours were defined as off hours, weekends and holidays. A preliminary investigation into the scope, frequency and severity of operations concerns revealed that issues ran the gamut from easily solvable to difficult and complex. A further, more in-depth investigation uncovered the existence and repetition of particular matters that offered high risk exposure. Because these issues occurred on the off tours and were neither tracked and trended nor considered as part of the panorama of risk, they were not included in a feedback loop to the Risk Management department and, thus, were lost opportunities for both process improvement and the integration of risk analysis into the strategic business challenges and goals of the organization.

A decision was made that educated and trained AODs would be hired to provide a senior, on site presence on the off tours and the leadership necessary to assist in the operationalization of the ERM process. AODs would identify and address the huge array of events that occurred on their watches then participate in the assessment of threat to the strategic objectives of the organization. The qualifications necessary to serve as an AOD included experience as a health care manager, higher education in a health care genre, and a deeprooted understanding of and appreciation for present day health care managerial literacies. Among the literacies, and because the organization is a safety net entity, demonstrating empathy and compassion were a must.

Several months after conceptualization and development, the AOD program was implemented. AODs were hired and underwent orientation inclusive of accreditation and regulatory standards and mandates, corporate and hospital policies and procedures, and ERM. They shadowed various department heads to get acclimated to the institution and services 
provided and were trained to meticulously document their activities and maintain a log for every shift. The AODs were scheduled to cover all shifts on all off tours.

Two years after implementation, the AOD program yielded invaluable information that contributed exponentially to the ERM endeavor. Risk issues and problems that had actual impact or considerable potential to impact ERM domains were identified and defined - some were identified during the initial investigation into the off tours - and categorized into risk domains for analysis. They were assessed and classified according to priority. Based upon the information derived from these phases of ERM, AOD mitigation was examined and risk responses/action plans were developed and put in place (see Table 1). The risk responses were monitored for efficacy and overall benefit to ERM and the organization. These risks would not have been captured as part of the global risk terrain but for the work of the AOD program.

Table 1. Risk Assessment \& Accountability Matrix

\begin{tabular}{|c|c|c|c|c|}
\hline Identified risks & Priority & $\begin{array}{l}\text { Risk domain } \\
\text { impact }\end{array}$ & AOD mitigation & Action plan \\
\hline $\begin{array}{l}\text { High profile events with ability for media } \\
\text { attention } \\
\text { - Shooting, criminal activity patient } \\
\text { - Extreme medical malpractice } \\
\text { - Elopement } \\
\text { - Union activity }\end{array}$ & High & $\begin{array}{l}\text { Operational } \\
\text { Strategic } \\
\text { Financial } \\
\text { Legal/regulatory } \\
\text { Human }\end{array}$ & $\begin{array}{l}\text { Leadership, direction, } \\
\text { notification to senior } \\
\text { management }\end{array}$ & $\begin{array}{l}\text { Develop and implement } \\
\text { standardized risk assessment } \\
\text { tool }\end{array}$ \\
\hline $\begin{array}{l}\text { Emergency management } \\
\text { - Acts of God } \\
\text { - Service interruptions } \\
\text { - Multiple trauma }\end{array}$ & High & $\begin{array}{l}\text { Operational } \\
\text { Strategic } \\
\text { Financial }\end{array}$ & $\begin{array}{l}\text { Leadership, coordination, } \\
\text { communication }\end{array}$ & $\begin{array}{l}\text { Formalize incident command } \\
\text { response for off tours with AOD } \\
\text { as incident commander; provide } \\
\text { training; update all emergency } \\
\text { response plans }\end{array}$ \\
\hline $\begin{array}{l}\text { Crisis management } \\
\text { - Equipment-related emergencies } \\
\text { - Medication shortage } \\
\text { - Supplies shortage }\end{array}$ & High & $\begin{array}{l}\text { Operational } \\
\text { Financial } \\
\text { Technological }\end{array}$ & $\begin{array}{l}\text { Leadership, coordination, } \\
\text { intervention, } \\
\text { acquisition }\end{array}$ & $\begin{array}{l}\text { Perform mock crisis } \\
\text { management drills focusing on } \\
\text { specific noted issues }\end{array}$ \\
\hline $\begin{array}{l}\text { Medical-social issues } \\
\text { - Domestic violence } \\
\text { - Child/elder abuse } \\
\text { - Homelessness } \\
\text { - Substance abuse } \\
\text { - Rape }\end{array}$ & Medium & $\begin{array}{l}\text { Legal/Regulatory } \\
\text { Human } \\
\text { Strategic }\end{array}$ & $\begin{array}{l}\text { Intervention and de-escalation, } \\
\text { coordination of care and } \\
\text { services, compassion and } \\
\text { empathy }\end{array}$ & $\begin{array}{l}\text { Provide specialized training } \\
\text { from field experts }\end{array}$ \\
\hline $\begin{array}{l}\text { Subject matter expertise needed } \\
\text { - Informed consent } \\
\text { - Confidentiality } \\
\text { - Special populations as developmentally } \\
\text { disabled and foster children } \\
\text { - Contagious illnesses }\end{array}$ & High & $\begin{array}{l}\text { Legal/regulatory } \\
\text { Human }\end{array}$ & $\begin{array}{l}\text { Facilitation of discussion } \\
\text { between clinical staff and } \\
\text { off-site subject matter experts, } \\
\text { promotion of interprofessional } \\
\text { collaboration }\end{array}$ & $\begin{array}{l}\text { Provide formal education } \\
\text { sessions for appropriate staff }\end{array}$ \\
\hline Patient transfers & Medium & $\begin{array}{l}\text { Operational } \\
\text { Legal/regulatory } \\
\text { Financial }\end{array}$ & Coordination, oversight & Perform mock patient transfers \\
\hline $\begin{array}{l}\text { Morgue and pathology-related issues } \\
\text { - Disposition of remains } \\
\text { - Autopsy } \\
\text { - Fetus and stillborn } \\
\text { - Bullets }\end{array}$ & Medium & $\begin{array}{l}\text { Operational } \\
\text { Human }\end{array}$ & $\begin{array}{l}\text { Oversight, coordination, } \\
\text { facilitation, delegation, } \\
\text { education }\end{array}$ & $\begin{array}{l}\text { Schedule meetings with } \\
\text { applicable external stakeholders } \\
\text { to foster better communication } \\
\text { when issues arise; educate } \\
\text { pathology staff }\end{array}$ \\
\hline $\begin{array}{l}\text { Patient/Family/Visitor/ Staff } \\
\text { complaints/concerns }\end{array}$ & High & $\begin{array}{l}\text { Operational } \\
\text { Strategic } \\
\text { Human }\end{array}$ & $\begin{array}{l}\text { De-escalation, intervention, } \\
\text { facilitation, conduct patient } \\
\text { comfort rounds to respond to } \\
\text { patient needs, conflict resolution }\end{array}$ & $\begin{array}{l}\text { Implement feedback mechanism } \\
\text { from Executive Grievance } \\
\text { Committee to Risk } \\
\text { Management/vice-versa }\end{array}$ \\
\hline Health information systems & High & $\begin{array}{l}\text { Operational } \\
\text { Strategic } \\
\text { Finance } \\
\text { Technological }\end{array}$ & Assessment, coordination & $\begin{array}{l}\text { Assure availability of extensive } \\
\text { IT services } 24 / 7 \text {; ensure all IT } \\
\text { security plans updated }\end{array}$ \\
\hline Patient flow & Medium & $\begin{array}{l}\text { Operational } \\
\text { Legal/regulatory } \\
\text { Human }\end{array}$ & $\begin{array}{l}\text { Direction, coordination, } \\
\text { facilitation }\end{array}$ & $\begin{array}{l}\text { Conduct full scale assessment to } \\
\text { be completed within three } \\
\text { months }\end{array}$ \\
\hline
\end{tabular}


This initial contribution by the AOD program to ERM did not just involve the AODs and risk leadership. While issues in the process of being identified were mitigated with the skillful resolve of the AODs, many problems were solved through a "confluence of perspectives" by management and staff led by AODs. The involvement of the AOD frequently deterred matters from spiraling out of control and inflicting financial consequence on the institution. Ultimately, risk management leadership took the information gained from the AOD program and shared it across functional disciplines to garner multiple perspectives and support for risk responses and collaboration among all managers in the organization. The goal of greater, effective management of these risks across the organization was in motion.

The AOD program was expanded to include additional shifts - days and evenings - Monday through Friday. While AODs became conduits of education for off tour staff, teaching tenets that ranged from policies and procedures to regulations and standards, they also became the champions of broadened learning, responsible for imparting constant and diligent reinforcement of patient satisfaction, patient safety and survey readiness issues. They educated staff on medication cart safety, electronic medical record security, responsiveness to clinical alarms, emergency management, hand- hygiene and patient identifiers. AODs were accountable for monitoring and validating off-hour activity and responsiveness to regulatory oversight plans of correction and associated surveillance, quality dashboards and indicators, prospective reviews of quality measures and life safety issues. The latter was an extensive but much needed undertaking.

The orientation and instruction provided to AODs included competency training. With a patient-centric emphasis, the training focused on team based leadership, interprofessional practice, servant leadership and emotional intelligence. ${ }^{[22-26]}$ This four prong methodology created greater complementarity between administration and clinical professionals which, in turn, generated greater accountability. Such training enabled AODs to more meaningfully impact the patient and provider experience, especially in the safety net milieu, and thus helped the organization move toward greater sustainability.

\subsection{AOD study: perceptions of AODs and hospital lead- ership}

To explore whether the AOD program afforded value and benefit to ERM and the organization, a two-step exploratory mixed-methods study was conducted. The study presents an appraisal of the AOD framework as perceived by the AODs and hospital leadership. Information was collected from the AODs and members of the senior management team and inductive qualitative content analysis was used to identify themes, similarities and differences associated with the discerned value of the AOD program specific to ERM as described by the participants. All study participants completed a demographic data questionnaire consisting of 6 questions, including age, gender, education, health care experience and areas of expertise.

The first step entailed administering a survey instrument to 10 individuals who served as AODs. The survey consisted of open-ended questions inquiring as to what the AODs perceived as the most value added by the AOD program, the least value added, and the contributions to ERM.

The second step involved conducting open-ended, semistructured interviews with four members of the senior leadership team. The interviews lasted between forty-five minutes to one hour and took place by telephone. Each interviewee was asked to identify the significance and worth derived from the AOD program. One interviewer conducted all interviews and recorded responses verbatim on hand-written field notes.

\section{RESULTS AND DISCUSSION}

\subsection{AOD perceptions}

Of the 10 AODs surveyed, 7 are male and 3 are female. The AODs ranged in age from 38 to 65 years and had a mean experience of 20 years as hospital administrators. The mean number of years of AOD experience in the health care field is 22 years. Areas of expertise outside of hospital administration included emergency medicine management, radiology, respiratory therapy, social work, surgical services, security, clinical laboratory management, and ambulatory care. Eight AODs were Master's degree trained and the majority held a Master of Public Administration or Master of Health Care Administration degree. The data collected provided insight into the worth of the AOD program as noted by the AODs themselves. Upon analysis four themes emerged.

\subsubsection{Leadership presence}

Leadership was, by far, the theme with the greatest amount of comment. AODs reported that the provision of an administrative leadership presence and visibility during off tours that mimicked Monday through Friday operations had a positive effect on staff, patients, families and visitors. There was a noticeable improvement in staff morale and team work because both clinical and administrative personnel had a senior manager to turn to for support, guidance and coordination. Staff relied on the AOD to synchronize interdisciplinary patient care measures and resolve operational difficulties which they were poorly equipped to handle. In turn, the AODs developed robust collaborative relationships with staff which forged trust, dedication and dependability. This open, two 
way communication fostered transparency throughout the organization which, in turn, promoted risk identification, assessment and resolution.

\subsubsection{Risk mitigation}

AODs unequivocally played a substantial role in mitigating risks. Due to their proactivity and ability to handle diverse patient, management and crisis issues which offered significant legal and regulatory exposure to the organization, they were able to stave off negative residual fall-out from the issues and pivot the organization toward loss alleviation and reduction. Participants noted that environment of care issues and patient grievances demanded persistent attention.

\subsubsection{Education}

A noteworthy portion of an AOD's time was spent educating, re-educating and reinforcing policies and procedures, Joint Commission and New York State Department of Health standards, and Centers for Medicare and Medicaid Conditions of Participation. This promoted immense professional development for both the recipient staff and the AOD. While the organization benefitted from the AOD program, the AOD concomitantly benefitted; the enormous demands placed on the AOD translated into knowledge expansion and career growth potential. AODs were appreciative for the breadth of experience the program afforded them.

\subsubsection{Facilitation}

One of the most important hats the AOD wore was catalyst of communication and action. AODs "got things done" because they "knew what to do and how to do it" in the majority of situations and, if they were at a loss for how to address an issue, they knew "to whom and where to turn".

\subsection{Leadership perceptions}

The senior leadership team interviewees consisted of the Vice President for Clinical Affairs, the Vice President for Patient Care Services, the Chief Medical Officer and the Director of Risk Management. Ages ranged from 53 to 73 years and the average number of years of health care experience is 31 years. Three of the senior leaders are men and all leaders held either a graduate degree in health care or a professional degree. The average number of years spent at the hospital organization is 25 years. The data collected provided overwhelming support that the program brought added value to the organization and its ERM approach.

Two themes emerged from the data: there was a noticeable difference in the culture of the organization due to the AOD program and the benefits of the program far exceeded anyone's highest expectations. During the interviews these two themes were often intermingled by the participants but several points consistently surfaced. Value was described as

Published by Sciedu Press a "huge bang for the buck" and "the operational efficiency of a well-oiled machine". Culture was "transformed from somewhat proactive to exceptionally proactive". Morale of all staff and personnel became "positively palatable". The leaders enthusiastically discussed how the AOD program had a spill-over effect on all tours in that all levels of personnel were aware of the work performed by the AODs and overwhelmingly supportive of their efforts.

Leadership recounted how they received compliments from staff for ensuring that the off tours had a professional, competent manager for leadership and guidance and stated that "staff felt we wanted them to succeed because we were giving them assistance to do so". The leaders all noted that the managerial competencies exhibited by the AODs were extraordinary: "They thought on their feet... and very quickly" and "they dealt with conflict seamlessly". AODs were described as professional, inspirational and connoisseurs of managerial skills.

Findings from this study support the hypothesis the AOD framework is a useful tool in ERM.

\section{Conclusions}

Risk does not occur in isolation. It occurs facility-wide, during all tours at all hours. Since patient, staff and visitor safety is everyone's responsibility, ERM allows for a wideranging, comprehensive approach to safety that involves deeper risk analysis, engagement of the entire health care organization, and structured, coordinated and cohesive mitigation responses to safety exposures.

The AOD program is a vital constituent of an ERM program. This is especially true for a safety net organization where patient care is further complicated by communication issues (limited English proficiency or lack of education), fragile social support systems (lack of family involvement or social services programs), patient impairment (substance/alcohol abuse or mental illness) or patients with significant social issues (homelessness or poverty). Having an AOD on site on off tours - when risks can and do emerge - is pivotal to ensuring that all organizational risks are captured, responded to and monitored. The program helps to ensure the sustainability of the organization.

There are several implications for future research. A quantitative study of the AOD program could be conducted to determine whether the framework yields cost-savings in litigation and other payouts for claims associated with risk exposure. Specifically, the study can examine the costs arising from actual and potential claims against the organization since the inception of the AOD program and prior to its inception, the level of involvement and intervention by AODs 
in the claims at issue, and AOD logs which provide comprehensive accounts of any and all matters which involved AOD effort. Claims would include pre-litigation matters, filed lawsuits and individual incidents identified by the ERM team as meeting or exceeding the organization's risk tolerance and appetite; costs would include incurred, incurred but not reported, and indemnity expenses. These data, along with the Risk Assessment and Accountability Matrix data, can be correlated to begin to establish organizational financial impact. It would also be fruitful to explore the perceptions of the staff, clinical and non-clinical, patients and visitors regarding the AOD program and the AODs.

\section{Limitations}

The study results are only generalizable to theory, not larger populations due to the small sample size and case study design. This primarily qualitative study was not designed to be a traditional case study to describe an entire organization or health care system in depth. The findings are specific to hospital administrators who manage safety net hospitals. There are limitations of relying on self-perceptions in the interviews and surveys and the survey instrument distributed to the AODs was not tested for validity or reliability albeit the questions were identical to the open-ended questions posed to senior leadership during their interviews.

\section{ACKNOWLEDGEMENTS}

The authors are grateful for the individuals who served as AODs and for their senior leadership colleagues, all of whom gave their time, comments and recommendations throughout the research process.

\section{CONFLiCTS OF INTEREST Disclosure}

The authors report no conflicts of interest.

\section{REFERENCES}

[1] Trubek L, Zabawa B, Galowitz P. Transformations in Health Law Practice: The Intersections of Changes in Healthcare and Legal Workplaces. Indiana Health Law Review. 2015; 12(1): 183. http: //dx.doi.org/10.18060/18962

[2] Zabawa B, Trubek L, Borisy-Rudin F. Adopting accountable care through the Medicare framework. Seton Hall L. Rev. 2012; 42: 1471 PMid: 23264971.

[3] Ramirez B, West D, Costell M. Development of a culture of sustainability in health care organizations. Journal of Health Organization and Management. 2013; 279(5): 665-672. PMid: 24341182. http://dx.doi.org/10.1108/JHOM-11-2012-0226

[4] Zuckerman H, Dowling I. The Managerial Role. Essentials of Healthcare Management. New York: Delmar; 1997.

[5] Guo K. Roles of Managers in Academic Health Centers: Strategies for the Managed Care Environment. Healthcare Manager. 2002; 20(3): 43-58. http://dx.doi.org/10.1097/00126450-20020 3000-00007

[6] Guo K. Entrepreneurship management in health services: an integrative model. Journal of Health and Human Services Administration 2005-2006; 28(3/4): 504-530.

[7] King AW. Managing organizational competencies for competitive advantage: The middle management edge. Academy of Management Executive. 2001; 15(2): 95-106. http://dx.doi.org/10.5465/A ME. 2001.4614966

[8] Papas J, Flaherty K, Wooldridge B. Achieving Strategic Consensus in the Hospital Setting: A Middle Management Perspective. Hospital Topics. 2003; 81(1): 15-22. PMid: 14513745. http: //dx.doi.org/10.1080/00185860309598011

[9] Hellriegel D, Jackson ES, Slocum J, et al. Management, $2^{\text {nd }}$ ed. Cape Town: Oxford University Press Southern Africa; 2004.

[10] Lussier RN. Management Fundamentals: Concepts, Applications, Skills Development, $3^{r d}$ Edition. Boston: Thomson South-Western; 2006.

[11] Pillay R. Defining competencies for hospital management: A comparative analysis of the public and private sectors. Leadership in Health
Services. 2008; 21(2): 99-110. http://dx.doi.org/10.1108/1 7511870810870547

[12] Gilmartin M, D'Aunno T. The INSEAD-NHS clinical strategists program: leadership development for strategic change. Paper presented at Sixth International Conference of Strategic Issues in Health Care Management, University of St. Andrews; 2004.

[13] Gomez-Mejia L, Balkin D, Cardy R. Management: People, Performance, Change. $2^{\text {nd }}$ ed. New York: McGraw-Hill; 2005.

[14] Grewer D. Changing leadership for changing times. Paper presented at Leadership in $21^{\text {st }}$ century. International conference on School Business Management, Cape Town; 2007.

[15] ACHE: 2016 Competencies Assessment Tool [Internet]. Chicago: American College of Health Care Executives; 2015. Available from: http://www.ache.org/pdf/nonsecure/careers/com petencies_booklet.pdf

[16] Zismer D. An argument for the Integration of Healthcare Management with Public Health Practice. Journal of Health Care Management. 2013; 58(4): 253-257. PMid: 24396945.

[17] Zismer D. Establishing brand loyalty in health care - what to learn from other industries. Physician Executive Journal. 2012; 58(3): 2226.

[18] Commission of Sponsoring Organizations of the Treadway Commission. Enterprise Risk Management - Integrated Framework [Internet]. 2004 [Cited 2015 Nov 18]. Available from: http://www. coso.o rg/Publications/ERM/COSO_ERM_ExecutiveSummary.pdf

[19] American Society for Health Care Risk Management Monograph Part 2. 2006. Available from: http://www.ashrm.org/pubs/whi te_papers.dhtml

[20] Behamdouni G, Millar K. Implementation of an Enterprise RiskManagement Program in a Community Hospital. Healthcare Quarterly. 2010; 13(10): 72-78. PMid: 20104041. http://dx.doi.org /10.12927/hcq. 2013.21618

[21] Consortium for Advanced Management - International. Integrated Risk and Crisis Management: The Landscape. Austin, Texas: McNair-Connolly, CJ \& Mahmood, Zakir; 2014. 
[22] Begun J, White K, Mosser G. Interprofessional care teams: the role of the healthcare administrator. Journal of Interprofessional Care. 2011; 25: 119-123. PMid: 20846046. http://dx.doi.org/10.31 $09 / 13561820.2010 .504135$

[23] Dye C. Leadership in Health Care: Values at the Top. Chicago: Health Administration Press; 2000.

[24] Freshman B, Rubino L. Emotional Intelligence: A Core Competency for Health Care Administrators. The Health Care Manager. 2002;
20(4): 1-9. PMid: 12083173. http://dx.doi.org/10.1097/001 26450-200206000-00002

[25] Rizzo M. Tools for Novice Health Care Clinical Administrators. The Health Care Manager. 2003; 24 (1): 5-11.

[26] Singer S, Hayes J, Cooper J, et al. A case for safety leadership training of hospital managers. Health Care Manager Review. 2011; 36(2): 188-200. PMid: 21317660. http://dx.doi.org/10.1097/HMR $.0 \mathrm{~b} 013 \mathrm{e} 318208 \mathrm{~cd} 1 \mathrm{~d}$ 